\title{
Analysis of Building Energy Efficiency and Wall Heat Preservation
}

\author{
Zhaoxia Han
}

Gansu Construction Vocational Technical College Lanzhou 730050

Keywords: Building energy conservation; Wall heat preservation; Energy saving materials

\begin{abstract}
Rapid development of economy speeds up the pace of China's urbanization. The gradual increasing of structures increases energy consumption. In order to adapt to the development of our country's economic society, the attention to environment protection is strengthened in our country. The energy consumption in construction industry is increasing, and thus reduces energy consumption in buildings; the building wall construction technology should be constantly improved. Improve the effect of wall heat preservation, at the same time, reduce energy consumption, improve people's living environment, promote the economic development of our country, and improve the construction of social benefits.

In the modern economic environment, building energy conservation and wall heat preservation both are the key parts in building, and their quality has important implications for construction quality. In the process of construction, to improve the level of building energy efficiency and the quality of wall insulation, advanced energy-efficient building materials and thermal insulation wall body must be used to lower the use of energy and pollution to the environment in the course of construction, and improve the quality of the wall.
\end{abstract}

\section{Building energy-saving materials}

With the rapid development of science and technology, the types of building energy-saving materials are increasing, and there are more than 20 existing building energy-saving materials in current market. Each kind of building energy-saving material has its own characteristics, new energy-efficient building material such as wire mesh fire core board and keel plasterboard have qualities like light, great toughness, good heat preservation performance. In the construction, new type energy saving material applied can greatly improve the seismic performance of buildings; Coal sintered brick and other new types of wall materials used in construction can play a good sound insulation effect, and use the above several kinds of new type building materials in construction will use lower energy consumption in the use of raw material quantity than traditional materials.

Fiber cement plywood, gypsum board and other building materials' upgrading also accelerate the formation of building wall system in our country, but compared with abroad, our country's new materials research and development ability is weak, which results in poor new type wall materials in China.So the development of new type wall materials is very slow.In construction, new wall materials can not only ensure engineering quality, shorten construction period, but also can greatly reduce the amount of cement mortar, therefore, the construction industry in our country should strengthen the research on new energy-efficient building materials, promote the development of construction industry in our country, and make the development of construction industry be adapted to the development of our country's economic society.

\section{New wall insulation energy-saving technology}

A.Inside the wall thermal insulation

Inside the wall thermal insulation is to set thermal insulation layer inside the wall. The main advantage of energy saving technology is convenient construction, at the same time, because all the thermal insulation material needed in the construction is arranged on the inside, in the process of construction, heat preservation material's weather ability and waterproof requirements are low.The 
main drawback of this construction technology is: because thermal insulation layer is arranged on the inner side of the wall, after the construction, with the passage of time, building interior cracks may occur, so the exterior wall insulation construction is used, minimize the amount of hanging wall body weights, at the same time this may cause some parts of the building beams produce cold bridge, thus cause heat loss, moreover, severe cases may occur condensation.

Now if external wall insulation technology is used in building construction, select materials such as benzene board, polystyrene particles, compaction of polystyrene as the main insulation materials. The article introduces the performance of three kinds of materials; special types of polystyrene material of construction technology are introduced. Compacting benzene board itself has the advantages of small thermal conductivity, density, coefficient of thermal conductivity of anti-crack mortar used before is as high as $0.93 \mathrm{~W}$ (m.k), and the coefficient of thermal conductivity of compacting benzene board is only $0.029 \mathrm{~W}$ (m.k).The former coefficient of thermal conductivity is up to 32 times of the latter.Polystyrene particles are mainly composed of two kinds of insulation materials:powder polystyrene particles and rubber powder.Rubber materials are commonly composed of several inorganic colloid silica fume:lime powder, , fly ash and cement together, and the heat preservation material import coefficient is $0.06 \mathrm{~W}(\mathrm{~m} . \mathrm{k})$, which is $1 / 16$ of the anti-crack mortar, and poly version of the particles has reached $1 / 22$ of the anti-crack mortar. Compared with anti-crack mortar, thermal conductivity coefficient of three kinds of material is very low.In use process,it may fully relief heat accumulation on the crack layer, which releases stress and heat loadthe system produced by the heat quickly to improve the durability of the wall.

In construction technology, take external wall thermal insulation wall with stucco gypsum polystyrene for example.It is one of the most commonly usedin exterior wall insulation construction.In the process of construction technology, the construction of exterior wall insourcing adopts the construction technology, and then the thermal insulation material used shall be flame retardant polystyrene foam board. In construction process, the binder used should be adhesive plaster, use powder made from mixing, admixture and construction of gypsum stucco, join the right amount of water in the process of construction to reduce the possibility of the wall cracks, and improve the quality of the wall.

B.Exterior insulation

Exterior insulation is to use thermal insulation material on the outside of buildings in construction so as to realize thermal insulation of the building.The exterior insulation technology can greatly reduce the impact of building outside environment (humidity, temperature, light, etc.) on the buildings so as to realize the protection of building main body. Main advantage of this technology in the construction process is on the basis of ensuring the wall heat preservation effect, improve the interior stability of building and moisture proof, at the same time it has certain inhibition effection mould formation and internal condensation, and can play a good energy saving effect. From the point of current construction situation, exterior insulation construction technology basically has the following kinds: 1 , external thermal insulation wall.The type of external thermal insulation wall uses the main material of rock (mine) cotton, styrene foam board and so on. 2, daub polystyrene particles exterior insulation wall body, the type wall presents network and network type two walls.If there is a net type of wall, pay attention to the choice of network enhancing. Glass fiber grid is a commonly used technique, and it has important application in anti-cracking cover soft.It also gets rapid development, mainly has the following advantages, on the one hand, make the stress get reasonable scatter, wall crack width obtains reasonable scatter, form some fine cracks, and the crack resistance of the wall is further enhanced. If cracking mortar is more used in the construction of the wall, because cracking mortar is alkaline, glass fiber grid cloth has strong alkali resistance, which has important significance to improve crack resistance of the walls. In addition, from wall durability analysis, it can be seen that high alkali resistant fiber has stronger durability than alkali grid cloth and non-alkali cloth.From the point of actual usage, it can satisfy at least 25 years. Therefore, in the choice of enhancing network, better choose high alkali grid cloth.On the basis of ensuring wall insulation energy-saving, improve the durability of the wall. 3, exterior insulation is expected to use polystyrene particles insulation wall body, and the type of insulation walls is mainly 
divided into anti-cracking layer and heat insulation layer.Thermal insulation material mainly use polystyrene particles lightweight aggregate, insulation powder, water mixed according to certain proportion to make gypsum, then daub.

C.Internal and external mixing heat preservation

Mixed inside and outside heat preservation is to combine moderate insourcing exterior wall and thermal insulation technology reasonably.According to actual conditions,carry onthermal insulation technology reasonably.If the environment is more suited to outside wall exterior insulation, exterior insulation is adopted, on the contrary, used external wall thermal insulation technology, thus make up for the two defects existing in thermal insulation technology, whichis a comprehensive strong thermal insulation technology. Mixed protection technology ofinside and outside the reasonable application, on the one hand, external wall thermal insulation technology is easy to damage building materials of faults, on the other hand also effectively avoid external wall insulation technology on the insulation, but internal and external mixing thermal insulation construction exists a fatal flaw.

From the operation, hybrid insulation construction can make construction speed improved to some extent. However, hybrid insulation on both inside and outside of the building will produce a serious damage.External thermal insulation wall structure in construction is mainly affected by indoor temperature changes.Because indoor temperature changes smaller, the temperature changing and formation stress are lesser too. Heat preservation practices within the construction of the wall are mainly affected by outdoor temperature. The change in temperature of outdoor and indoor is bigger, and it will make the wall for a long period of time be in an unstable environment temperature, the temperature change will form a larger stress, therefore in the process of wall insulation construction, adopt the method of internal and external mixing thermal insulation construction, which will lead to different parts deformation of the outer wall and different produce different size on deformation rate.This structure is in an unstable environment for a long time, all year round temperature change will lead to wall cracks, reduce the service life of buildings, and people are aware of the defects of internal and external mixing heat preservation, so the construction method is seldom used in construction.

\section{Heat preservation and heat insulation technology development}

Since last century $60 \mathrm{~s}$, heat preservation and heat insulation wall had certain development in our country.Although in the development process, it has made some achievements, still compared with the developed countries,there is still a certain gap in the development of heat preservation and heat insulation wallin our country.In order to make heat preservation and heat insulation wall technology be able to get a better development in our country, we must clear the development direction of wall insulation energy-saving technology. From the current heat preservation and heat insulation technology development trends, major developments are the following: 1.Improve waste recovery formed in industrial production process, and on the basis of our country development, try to block the development of products. Building block is used in the construction of major building materials, in the process of production, reasonable use of industrial waste turned into blocks, and are applied in building materials.It not only played a rolein the protection of ecological environment, at the same time, waste is an ideal technology for sustainable development, and it has received applications in modern construction industry development, and will get more extensive application in the future. 2.Speed up the development of composite wall material. The use of composite wall material is essential to realize objective of building energy efficiency in China. At present,concrete composite materials are given priority to in the building, and common heat preservation performance is poor. Therefore, make composite materials research and development through the principle of overall planning, scientific layout.The development of a kind of composite material with basic performance of concrete building materials, and has good heat preservation performance has a long-term significance to improve building heat preservation and heat insulation technology in our country. 3.Improve wall standard, to some degree, at present our country existing heat preservation and heat insulation wall specification has played a certain restriction on its technological development, and this also has certain constraints on the standardization of heat 
preservation and heat insulation wall, thus, develop a compatible standard with energy-saving building wall technology in China is necessary.

\section{Conclusion}

Although China is humongous, because of large population, there is a shortage of resources per capita, so energy problems must be paid attention to in the development of overweight constraints on China's economic development. Based on this, in the process of construction, heat preservation material and improvement of wall body energy saving construction technology should be constantly updated to reduce energy consumption in construction process. In energy-efficient building construction process, exterior wall has important influence factor to wall insulation energy-saving, so pay attention to the reasonable application of construction method for thermal insulation, and improve the quality of engineering. At the same time, because of the particularity of work, people have to build up the idea of protecting the environment and saving resources, realize the harm done by energy waste to promote the rapid development of construction industry in our country.

\section{References}

[1]ZouChunqiu. Wall thermal insulation of building energy efficiency [J]. Science and Technology guide Wealth, 2011, 10 (5) : 12-13.

[2] Wang Yan. Building energy efficiency and wall heat preservation [J]. Journal of Urban Architecture, 2014, 12 (15) : 25-26.

[3] Yang Jinhui. Introduction to building energy efficiency and wall heat preservation [J]. Science and Technology, 2014, 8 (6) : 310-311.

[4] Chen Xiang. Building energy efficiency and wall heat preservation [J]. Science and Technology, 2014, 13 (5) : 163-163.

[5] $\mathrm{Hu}$ Xianming. Building external wall thermal insulation technology and building energy efficiency [J]. Chinese Local-style Dwelling Houses (below the ten-day), 2013, 8 (6) : 136-137.

[6] Zhang Long. Introduction to exterior wall thermal insulation technology and energy saving materials [J]. Journal of Information Science and Technology, 2013, 10 (18) : 312-313.

[7] ZhengYuhua. Our country building external wall thermal insulation and insulation energy-saving problem research [J]. Chinese Local-style Dwelling Houses, 2012, 13 (6) : 88-90. 